\title{
Secular trends in opportunistic infections, cancers and mortality in patients with AIDS during the era of modern combination antiretroviral therapy
}

\author{
E Sezgin (D), ${ }^{1,2}$ ML Van Natta, ${ }^{2}$ JE Thorne, ${ }^{2,3}$ MA Puhan ${ }^{2,4}$ and DA Jabs ${ }^{2,5,6}$ for the Longitudinal Studies of the Ocular \\ Complications of AIDS (SOCA) Research Group \\ ${ }^{1}$ Laboratory of Nutrigenomics and Epidemiology, Department of Food Engineering, Izmir Institute of Technology, Izmir, \\ Turkey, ${ }^{2}$ Department of Epidemiology, The Johns Hopkins University Bloomberg School of Public Health, Baltimore, MD, \\ USA, ${ }^{3}$ Department of Ophthalmology, The Wilmer Eye Institute, The Johns Hopkins University School of Medicine, \\ Baltimore, MD, USA, ${ }^{4}$ Epidemiology, Biostatistics and Prevention Institute, University of Zurich, Zurich, Switzerland, \\ ${ }^{5}$ Department of Ophthalmology, Icahn School of Medicine at Mount Sinai, New York, NY, USA and ${ }^{6}$ Department of \\ Medicine, Icahn School of Medicine at Mount Sinai, New York, NY, USA
}

\section{Objectives}

The aim of the study was to estimate the incidence of, determine risk factors for, and investigate the consequences of opportunistic infections (OIs) and malignancies among patients with the acquired immune deficiency syndrome (AIDS) in the era of modern combination antiretroviral therapy (cART).

Methods

Three enrolment periods (1998-2002, 2003-2005 and 2006-2012), corresponding to changes in predominant cART regimens, were compared among 1889 participants enrolled in a prospective cohort study, the Longitudinal Study of Ocular Complications of AIDS (LSOCA). Incidences of AIDS-related OIs and cancers were estimated. Multivariate logistic and Cox regression models were used to determine the effect of demographic and clinical characteristics on OIs and mortality.

Results

Between participants enrolled in the 1998-2002 and 2006-2012 enrolment periods, the incidence of OIs decreased from 27 per 1000 person-years (PY) to 11 per 1000 PY $(P<0.001)$, and mortality decreased from 41 per 1000 PY to 18 per 1000 PY $(P<0.0001)$, corresponding to improvements in cART regimens.

\section{Conclusions}

Improvements in cART regimens led to a progressive decline in the incidence of OIs and mortality between 1999 and 2013 among patients with AIDS in the era of modern cART.

Keywords: AIDS, AIDS-related cancer, HIV, mortality, opportunistic infection

Accepted 26 January 2018

\section{Introduction}

With the advent of modern combination antiretroviral therapy (cART) in the mid-1990s, the incidences of HIVassociated opportunistic infections (OIs), cancers, and

Correspondence: Dr Efe Sezgin, Izmir Institute of Technology, Laboratory of Nutrigenomics and Epidemiology, Urla, Izmir 35430, Turkey. Tel: (90) 232750 6281; fax: (90) 232750 6196; e-mail: efesezgin@iyte.edu.tr and

Dr Douglas A Jabs, Department of Ophthalmology, The Icahn School of Medicine at Mount Sinai, One Gustave L. Levy Place, Box 1183, New York, NY 10029, USA. Tel: 212241 6752; fax: 212241 5764; e-mail: douglas.jabs@mssm.edu mortality have decreased substantially [1-15]. Despite the decline in HIV-associated OIs and cancers over the last two decades, their incidences never reached those of people without HIV infection, and they remain a leading cause of mortality and morbidity [9,16-25].

Because recommendations for cART are to start it at CD4 T-cell levels well above those at which the acquired immunodeficiency syndrome (AIDS) would be diagnosed and prior those increasing the risk for OIs, most studies demonstrating the benefits of cART on OIs involve cohorts of patients including patients with earlier stages of HIV infection. Among those at risk for OIs, 
prophylactic antimicrobial therapy [such as against Pneumocystis jirovicii pneumonia (PJP) and Mycobacterium avium complex (MAC)] also have been effective in decreasing the incidence of OIs $[5,7,8]$. In the modern cART era, OIs still occur, albeit at a substantially reduced rate, and are associated with lower CD4 T-cell counts and higher amounts of circulating HIV RNA in the blood (HIV load) $[20,26,27]$. Because most of the studies demonstrating the beneficial effect of cART on the incidence of OIs come from cohorts with earlier stages of HIV infection, there are few data on secular trends in the incidence of OIs among patients with the late stage of HIV infection, namely AIDS [28-31]. However, AIDS continues to occur, largely because of late diagnosis of HIV infection, but also because of failure in some patients to suppress HIV replication with cART [15,32-34].

The Longitudinal Study of the Ocular Complications of AIDS (LSOCA) is a 15-year prospective cohort study conducted in the era of modern CART, and is unique in that it only enrolls patients with AIDS, and with a wide range of immune function, from diverse HIV risk groups. As such, it provides a unique opportunity to evaluate the effect of cART and changes in cART regimens on the incidence of AIDS-related OIs, cancers and mortality among patients with late-stage HIV infection, namely AIDS.

\section{Patients and methods}

LSOCA is a prospective observational study of patients with AIDS conducted in the era of modern cART $[35,36]$. Patients aged $\geq 13$ years with a diagnosis of AIDS according to the 1993 definition of the Centers for Disease Control and Prevention (CDC) case surveillance were enrolled between 1 September 1998 and 31 December 2011 at 19 centres across the USA. Only patients without an ocular OI (namely cytomegalovirus (CMV) retinitis) are included in this analysis to avoid enrolment bias. After the initial recruitment period, rolling recruitment was used to provide ongoing information on changes in the AIDS epidemic. Demographic information and a detailed medical history, including all OIs and current and previous ART, were obtained at enrolment and confirmed by record review as appropriate. A limited medical and a complete ophthalmic examination were performed [35,37]. Enrolment laboratory testing included a complete blood count, serum chemistries, and measurements of CD4 T-cell counts and HIV loads. The diagnosis of OIs was made according to the AIDS Clinical Trials Group guidelines [31], and information was collected on OIs and AIDS-related cancers; and for the purposes of this analysis, OIs and cancers were those considered AIDS-defining based on the CDC revised 1993 AIDS case surveillance definition and the 5 December 2008
CDC OI reporting guidelines (http://www.cdc.gov/mmwr/ preview/mmwrhtml/rr5710a2.htm) [38,39]. Participants were seen every 6 months in follow-up. The study and the protocol were approved by institutional review boards at all participating centres; enrolled participants provided written informed consent; and the study and procedures adhered to the Declarations of Helsinki.

Combination ART was defined as any of the following: treatment with any three antiretrovirals, one of which was either a protease inhibitor, a nonnucleoside reverse transcriptase inhibitor (NNRTI) or a fusion, integrase or entry inhibitor; any three nucleoside reverse transcriptase inhibitors, one of which was abacavir or tenofovir (except for the regimens abacavir/tenofovir/lamivudine and didanosine/ tenofovir /lamivudine); two full-dose protease inhibitors; a boosted protease inhibitor with either an NNRTI or a fusion inhibitor; or an integrase inhibitor combined with either a protease inhibitor, NNRTI, entry inhibitor or fusion inhibitor. If zidovudine and stavudine were present in the same regimen, they were removed from that regimen's total antiretroviral count because of their known antagonism [28].

In order to assess secular changes in the incidence of OIs and malignancies, participants were grouped into three recruitment periods: 1998-2002; 2003-2005 and 2006-2012. These enrolment periods were selected to coincide with changes in the predominant cART regimen being used (Table S1). Because of the initial bolus of recruitment, the initial recruitment period contained slightly over $60 \%$ of the participants.

Patient data collected and reported to the Coordinating Center as of 31 December 2012 were included in the analyses. Mortality analysed throughout the study represents all-cause mortality. Follow-up time was calculated as the time from study entry to first incidence, to death, or to 31 December 2012 for patients under active follow-up, or to the date of the last study contact for patients who were lost to follow-up. Mortality and incidence rates were calculated as the number of deaths and number of AIDS-defining conditions divided by the number of person-years at risk. Relative risks were estimated with Cox proportional hazards. Survival analyses were performed with staggered entries based on time since diagnosis of AIDS. Analyses were performed with the SAS/STAT ${ }^{\circledR}$ version 9.3 (SAS Institute, Inc., Cary, NC, USA) and STATA version 12.0 (StataCorp LP, College Station, TX, USA) software packages.

\section{Results}

Characteristics of the study population

Enrolment characteristics of the three enrolment cohorts of LSOCA are shown in Table 1 . Of the 1889 participants, 
1180 were enrolled in the first cohort, 329 in the second, and 380 in the third. Consistent with changes in the AIDS epidemic, there was a decrease in the proportion of participants who were white and whose HIV transmission category was male-to-male sexual contact after the first enrolment period. There was also an increase in the proportion of participants whose AIDS-defining condition was CD4 T-cell lymphopaenia, as opposed to an OI, in the third recruitment period $v s$. the first and second recruitment periods (74\% vs. 64\% and 62\%, respectively; $P<0.001)$. Participants in the third recruitment period had higher enrolment CD4 T-cell counts than those in the first two recruit periods (median 282 vs. 174 and 197 cells $/ \mu \mathrm{L}$, respectively; $P<0.0001$ ) and lower HIV loads (median 2.0 vs. 3.3 and $2.6 \log _{10}$ HIV RNA copies/ $\mathrm{mL}$, respectively; $P<0.0001$ ). Although there was an apparent increase in cART use prior to enrolment with each successive recruitment period $(76 \%$ vs. $83 \%$ vs. 94\%, respectively; $P<0.0001$ ), there was no significant difference in the use of cART during follow-up among the three groups, and overall 97\% of participants received cART during follow-up.

Incidence of opportunistic infections and AIDS-associated malignancies

There were 135 incident OI events during 13689 personyears (PY) of observation (20 per 1000 PY). The incidence

Table 1 Patient characteristics at enrolment in the Longitudinal Study of the Ocular Complications of AIDS cohort

\begin{tabular}{|c|c|c|c|c|c|}
\hline \multirow[b]{2}{*}{ Characteristic } & \multicolumn{3}{|l|}{ Enrolment cohort } & \multirow[b]{2}{*}{ Total $(n=1889)$} & \multirow[b]{2}{*}{$P$-value ${ }^{*}$} \\
\hline & 1998-2002 $(n=1180)$ & $2003-2005(n=329)$ & $2006-2012(n=380)$ & & \\
\hline Age (years) [median (25th, 75th percentile)] & $42(37,47)$ & $44(40,51)$ & $46(40,52)$ & $43(38,49)$ & $<0.0001$ \\
\hline Male $(\%)$ & 81 & 77 & 80 & 80 & 0.36 \\
\hline \multicolumn{6}{|l|}{ Race $(\%)$} \\
\hline White & 50 & 34 & 39 & 45 & \multirow[t]{3}{*}{$<0.0001$} \\
\hline African American & 33 & 45 & 48 & 38 & \\
\hline Other & 17 & 20 & 13 & 17 & \\
\hline \multicolumn{6}{|l|}{ HIV transmission category $(\%)$} \\
\hline Male-to-male sexual contact & 57 & 48 & 51 & 54 & \multirow[t]{3}{*}{0.02} \\
\hline Injecting drug use ${ }^{\dagger}$ & 12 & 18 & 16 & 14 & \\
\hline Other & 31 & 34 & 33 & 32 & \\
\hline Any insurance (\%) & 82 & 89 & 84 & 83 & 0.08 \\
\hline $\begin{array}{l}\text { Time since AIDS diagnosis (years) } \\
\text { [median (25th, 75th percentile)] }\end{array}$ & $4.0(1.6,6.4)$ & $5.5(1.7,8.7)$ & $4.7(1.1,8.2)$ & $4.3(1.6,7.2)$ & $<0.0001$ \\
\hline \multicolumn{6}{|l|}{ AIDS diagnosis category (\%) } \\
\hline CD4 T-cell lymphopaenia & 64 & 62 & 74 & 65 & \multirow[t]{2}{*}{$<0.001$} \\
\hline Opportunistic infection or malignancy & 32 & 34 & 23 & 31 & \\
\hline \multicolumn{6}{|l|}{ Enrolment CD4 T-cell count (cells/ $\mu \mathrm{L}$ ) } \\
\hline Median (25th, 75th percentile) & $174(66,325)$ & $197(104,380)$ & $282(124,427)$ & $197(80,358)$ & $<0.0001$ \\
\hline Per cent of participants $<200$ & 55 & 50 & 37 & 51 & \multirow[t]{3}{*}{$<0.0001$} \\
\hline Per cent of participants $200-500$ & 34 & 35 & 44 & 36 & \\
\hline Per cent of participants $>500$ & 11 & 14 & 19 & 13 & \\
\hline \multicolumn{6}{|l|}{ Nadir CD4 T-cell count (cells/ $\mu \mathrm{L}$ ) } \\
\hline Median (25th, 75th percentile) & $43(13,112)$ & $44(14,101)$ & $50(16,133)$ & $44(14,115)$ & 0.29 \\
\hline Per cent of participants $<50$ & 53 & 53 & 50 & 53 & \multirow[t]{2}{*}{0.24} \\
\hline Per cent of participants $\geq 50$ & 47 & 47 & 40 & 47 & \\
\hline \multicolumn{6}{|l|}{ Enrolment HIV load ( $\log _{10}$ copies/mL) } \\
\hline Median (25th, 75th percentile) & $3.3(2.4,4.8)$ & $2.6(1.9,4.4)$ & $2.0(1.7,2.7)$ & $2.7(1.9,4.6)$ & $<0.0001$ \\
\hline Per cent of participants $<2.6$ & 27 & 42 & 63 & 37 & \multirow[t]{3}{*}{$<0.0001$} \\
\hline Per cent of participants $2.6-5$ & 32 & 29 & 20 & 29 & \\
\hline Per cent of participants $\geq 5$ & 40 & 29 & 17 & 33 & \\
\hline \multicolumn{6}{|l|}{ Maximum prior HIV load $\left(\log _{10}\right.$ copies $\left./ \mathrm{mL}\right)$} \\
\hline Median (25th, 75th percentile) & $5.3(4.7,5.7)$ & $5.3(4.7,5.8)$ & $5.3(4.8,5.7)$ & $5.3(4.7,5.7)$ & 0.63 \\
\hline Per of cent participants $<5$ & 11 & 11 & 10 & 11 & \multirow[t]{2}{*}{0.38} \\
\hline Per cent of participants $\geq 5$ & 89 & 89 & 90 & 90 & \\
\hline \multicolumn{6}{|l|}{ ART (\%) } \\
\hline Any ART prior to enrolment & 76 & 83 & 94 & 81 & $<0.0001$ \\
\hline Receiving cART at enrolment & 82 & 88 & 92 & 85 & $<0.0001$ \\
\hline Any cART during follow-up & 96 & 96 & 97 & 97 & 0.14 \\
\hline
\end{tabular}

ART, antiretroviral therapy; cART, combination antiretroviral therapy (see Methods).

${ }^{*} P$-values comparing three cohorts.

${ }^{\dagger}$ The injecting drug use category includes persons with any injecting drug use. 
of specific OIs by enrolment cohort is shown in Table S2 and was lower for participants enrolled in the third enrolment period than for those in the first two (11 per 1000
PY vs. 27 and 23 per 1000 PY, respectively; $P<0.001$ ). When analysed by calendar year, the incidence of total OIs decreased from 1999 to $2013(P<0.0001)$ but never

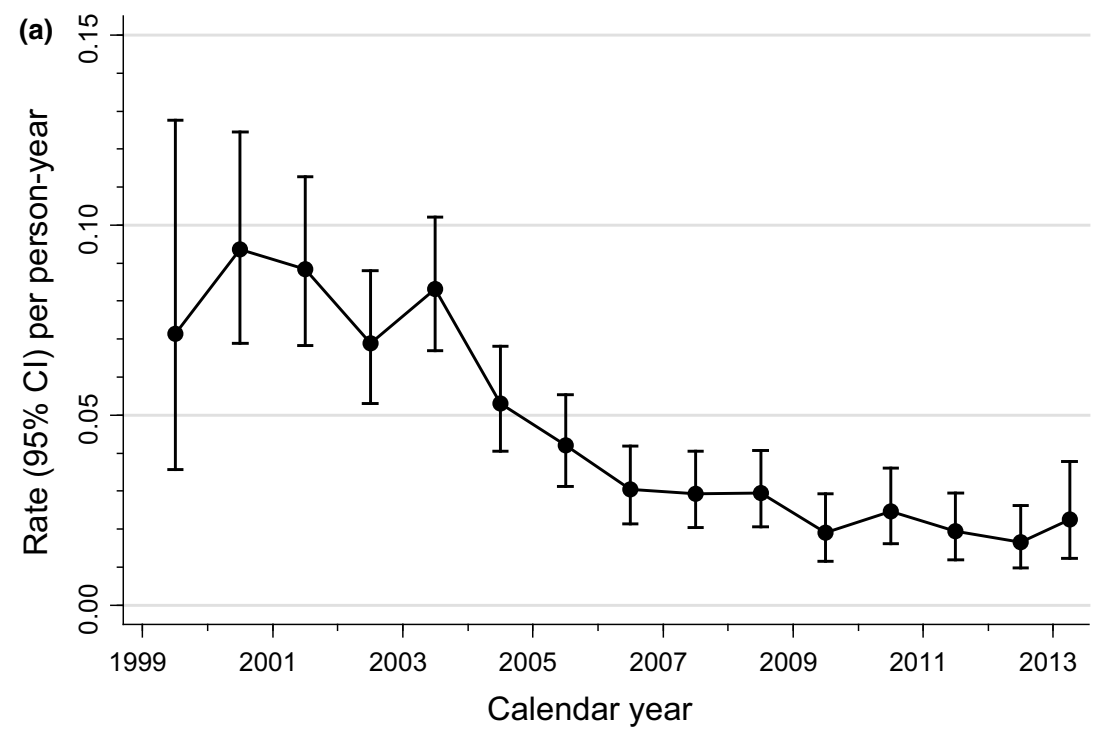

(b)

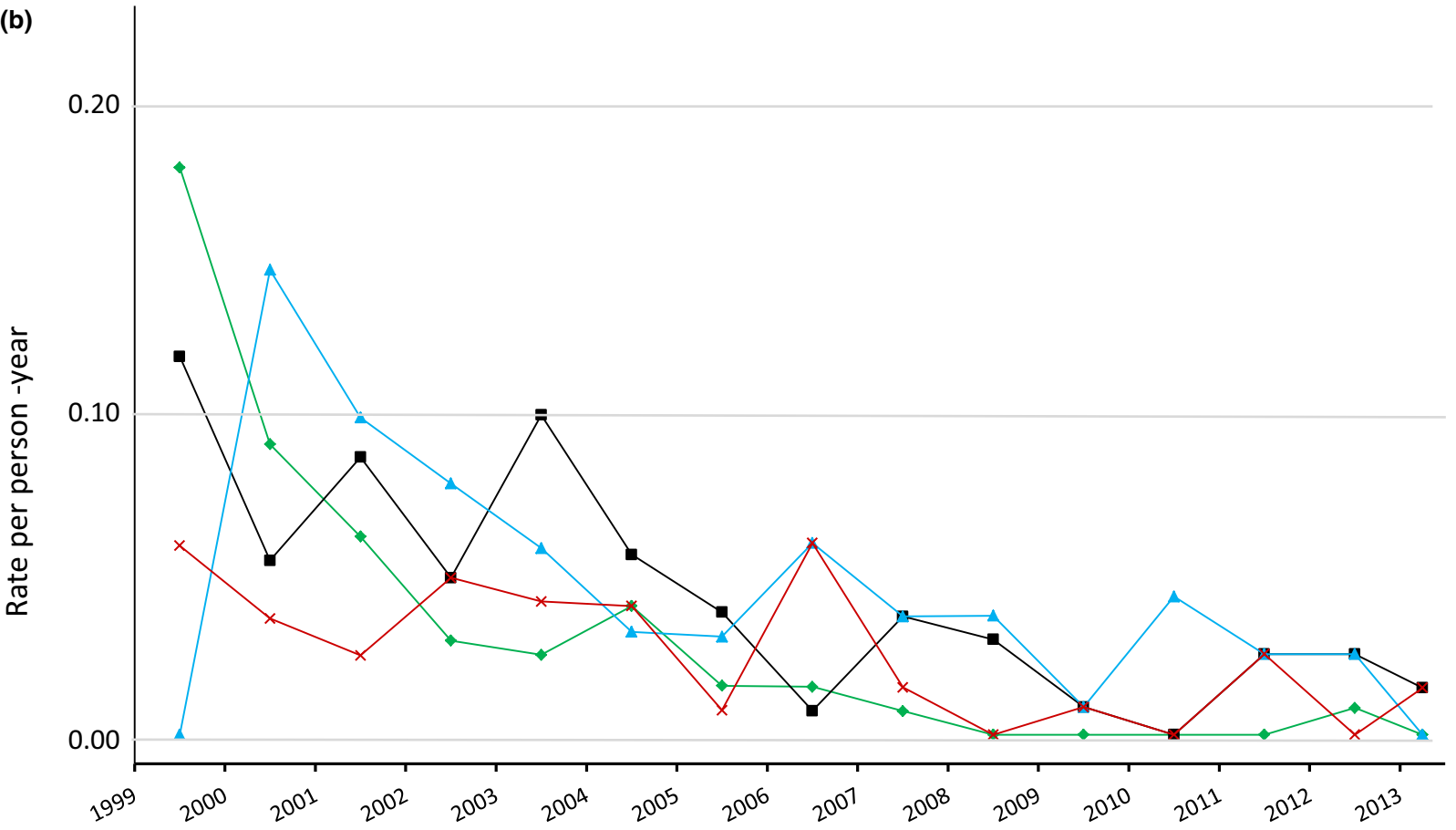

Calendar year
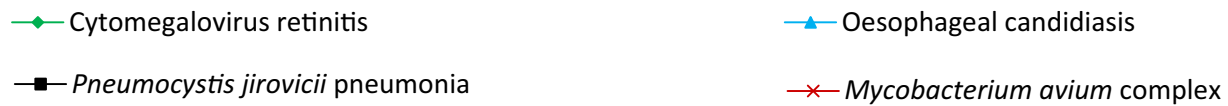

Fig. 1 Incidence of (a) total and (b) selected most common AIDS-defining opportunistic infections by calendar year. Cl, confidence interval. 
reached zero (Fig. 1a). The incidences of the four most common OIs (Fig. 1b) decreased from 1999 to 2007 $(P<0.001)$ and then remained constant until 2013 without reaching zero.

There were 45 incident AIDS-associated malignancies during 13689 PY of follow-up (incidence 3.7 per 1000 PY). The cancer incidence rate decreased by successive enrolment cohort (Table 2 and Table S2). Kaposi sarcoma and lymphomas rates were similar, with a slight decline in the last cohort, and both had similarly low rates throughout.

Risk factors for incident OIs and AIDS-related malignancies are shown in Table 2. Being in the first enrolment cohort, black race, enrolment CD4 T cell count $<200$ cells/ $\mu \mathrm{L}$, lower nadir CD4 T-cell count prior to enrolment, higher HIV load at enrolment, higher maximum HIV load prior to enrolment, and not being on cART were associated with increased risk for OIs (Table 2). Risk factors associated with an increased incidence of AIDS-related cancers included enrolment CD4 T-cell count $<200$ cells $/ \mu \mathrm{L}$, higher HIV load at enrolment, and not being on any ART (Table 2).

The median $(25 \%, 75 \%)$ CD4 T-cell count was 100 (23, 232) cells $/ \mu \mathrm{L}$ at the first follow-up visit at which an AIDS-defining illness (any OI or cancer) was reported and $29 \%$ of the OI incidences were observed among patients with a CD4 T-cell count $>200$ cells $/ \mu \mathrm{L}$. The median HIV load was $4.0(2.3,5.1) \log _{10}$ copies/mL at the first followup visit at which an AIDS-defining illness was reported and $14 \%$ of the OI incidences were observed among patients with HIV loads $<400$ copies $/ \mathrm{mL}$.

\section{Mortality}

The overall mortality during follow-up was 37 per 1000 PY. The mortality rate decreased from 2002 to 2013 (Fig. 2a; regression $P<0.0001$ ). There was a significant decrease in mortality in the third enrolment cohort $v s$. the first two (18 per 1000 PY vs. 34 and 41 per 1000 PY, respectively; Fig. 2b). The relative risk (RR) for mortality comparing the first enrolment cohorts vs. the third was $0.46(P<0.0001)$. Enrolment risk factors for mortality are shown in Table 3. In addition to enrolment cohort, the presence of any AIDS-related malignancy at enrolment $(\mathrm{RR}=1.62 ; P=0.007)$ was associated with and increased mortality.

\section{Discussion}

The LSOCA cohort is unique in that it enrolled only patients with AIDS, with a wide range of immune function, and was not HIV transmission category restricted
[35]. As such it is uniquely positioned to evaluate the impact of cART on AIDS-related OIs, cancers and mortality among patients with late-stage HIV infection, whereas most other cohorts evaluate these outcomes among patients including earlier stages of HIV infection. Our

Table 2 Association of clinical characteristics at enrolment with the incidence of AIDS-defining opportunistic infections (OIs) and cancers

\begin{tabular}{|c|c|c|c|c|}
\hline & \multicolumn{2}{|c|}{$\begin{array}{l}\text { Any } 0 \mathrm{I} \text { incidence } \\
(n=135)\end{array}$} & \multicolumn{2}{|c|}{$\begin{array}{l}\text { Any cancer } \\
\text { incidence } \\
(n=45)\end{array}$} \\
\hline & $\mathrm{RR}^{*}$ & $P^{\dagger}$ & $\mathrm{RR}^{*}$ & $P^{\dagger}$ \\
\hline \multicolumn{5}{|l|}{ Enrolment cohort } \\
\hline 1998-2002 & Ref & & Ref & \\
\hline $2003-2005$ & 0.83 & 0.48 & 0.84 & 0.69 \\
\hline 2006-2012 & 0.37 & 0.01 & 0.58 & 0.31 \\
\hline \multicolumn{5}{|l|}{ AIDS diagnosis category } \\
\hline CD4 T-cell lymphopaenia & Ref & & Ref & \\
\hline Opportunistic infection or malignancy & 0.85 & 0.48 & 1.36 & 0.37 \\
\hline \multicolumn{5}{|l|}{ Race } \\
\hline White & Ref & & Ref & \\
\hline Black & 1.65 & 0.008 & 0.66 & 0.22 \\
\hline Other & 0.68 & 0.22 & 0.84 & 0.69 \\
\hline \multicolumn{5}{|l|}{ Sex } \\
\hline Male & Ref & & Ref & \\
\hline Female & 1.22 & 0.37 & 0.99 & 0.97 \\
\hline \multicolumn{5}{|l|}{ Enrolment median age } \\
\hline$\geq 43$ years & Ref & & Ref & \\
\hline$<43$ years & 1.35 & 0.09 & 0.98 & 0.94 \\
\hline \multicolumn{5}{|l|}{ HIV transmission category } \\
\hline Male-to-male sexual contact & Ref & & Ref & \\
\hline Injecting drug use & 0.86 & 0.62 & 0.57 & 0.29 \\
\hline Other & 1.06 & 0.79 & 0.58 & 0.13 \\
\hline \multicolumn{5}{|l|}{ Enrolment CD4 count } \\
\hline$\geq 500$ cells $/ \mu \mathrm{L}$ & Ref & & Ref & \\
\hline 200-500 cells/ $\mu \mathrm{L}$ & 1.12 & 0.78 & 1.56 & 0.56 \\
\hline$<200$ cells $/ \mu \mathrm{L}$ & 3.31 & 0.001 & 3.59 & 0.08 \\
\hline \multicolumn{5}{|l|}{ Nadir CD4 count } \\
\hline$\geq 50$ cells $/ \mu \mathrm{L}$ & Ref & & Ref & \\
\hline$<50$ cells $/ \mu \mathrm{L}$ & 1.71 & 0.003 & 0.89 & 0.72 \\
\hline \multicolumn{5}{|l|}{ Enrolment HIV load } \\
\hline$<2.6 \log _{10}$ copies $/ \mathrm{mL}$ & Ref & & Ref & \\
\hline $2.6-5 \log _{10}$ copies $/ \mathrm{mL}$ & 1.78 & 0.04 & 3.06 & 0.02 \\
\hline$\geq 5 \log _{10}$ copies $/ \mathrm{mL}$ & 4.74 & $<0.0001$ & 4.15 & 0.002 \\
\hline \multicolumn{5}{|l|}{ Maximum prior HIV load } \\
\hline$<5 \log _{10}$ copies $/ \mathrm{mL}$ & Ref & & Ref & \\
\hline$\geq 5 \log _{10}$ copies $/ \mathrm{mL}$ & 2.27 & 0.01 & 2.04 & 0.24 \\
\hline \multicolumn{5}{|l|}{ Enrolment $A R T^{\S}$} \\
\hline No ART & Ref & & Ref & \\
\hline ART (no cART) & 0.70 & 0.32 & 0.57 & 0.34 \\
\hline cART & 0.37 & $<0.0001$ & 0.31 & 0.002 \\
\hline
\end{tabular}

*Relative risk; Cox models with staggered entries based on time since diagnosis of AIDS.

tikelihood ratio $\chi^{2} P$-values.

\#njecting drug use category includes persons with any injecting drug use.

${ }^{\S}$ No ART is no antiretroviral usage reported at study entry; ART (no CART) is any antiretroviral treatment that is not considered CART; cART is at least two different antiretrovirals in combination that qualify as cART according to the modern classifications (see Methods for details). 
(a)

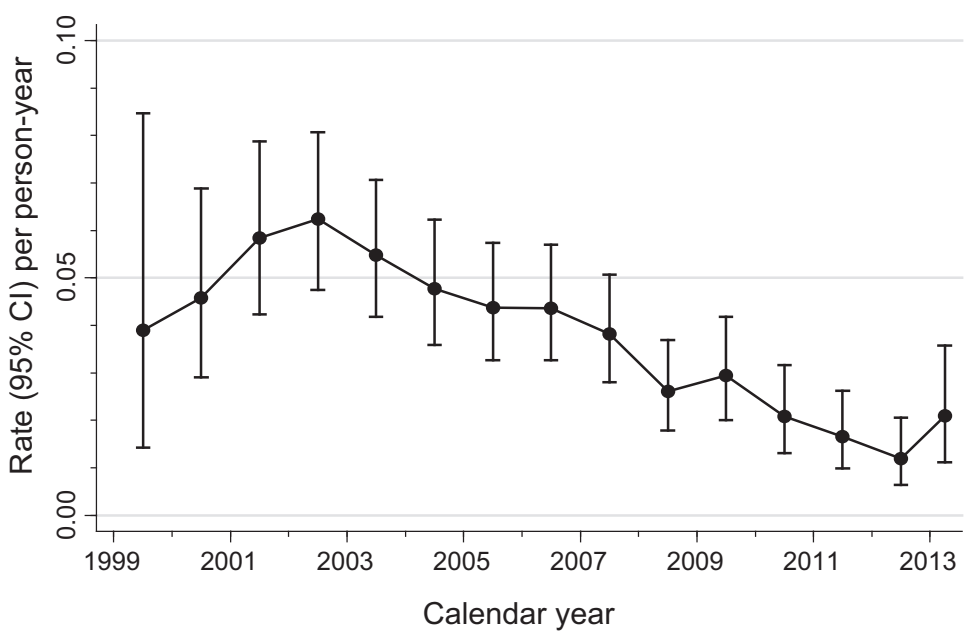

(b)

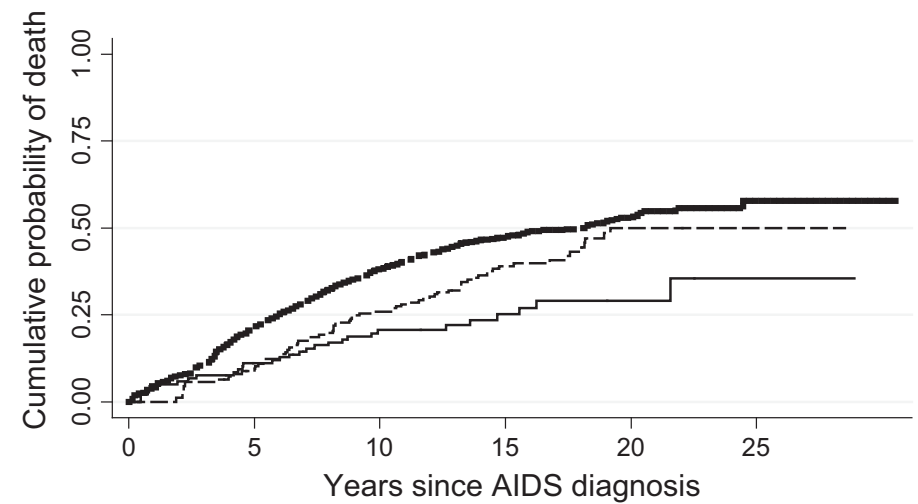

\begin{tabular}{|c|c|c|c|c|c|c|}
\hline \multicolumn{7}{|c|}{ Number at risk } \\
\hline 1998-2002 & 88 & 610 & 721 & 426 & 108 & 14 \\
\hline $2003-2005$ & 18 & 124 & 142 & 82 & 26 & 3 \\
\hline $2006-2012$ & 17 & 106 & 84 & 44 & 11 & 8 \\
\hline
\end{tabular}

Fig. 2 Incidence of any mortality by calendar year (a) and mortality comparison among enrolment cohorts (b). Cl, confidence interval.

data demonstrate a secular decline in the incidence of OIs and mortality in a cohort of patients with AIDS over the time period 1998-2013, with the largest declines in OIs occurring before 2007. Previous incidence studies of OIs in HIV-infected cohorts (i.e. not restricted to AIDS at enrolment) reported a sharp decline in the 1992-1997 period followed by a more gradual decline in 1998-2002 and low, stabilized incidences in the 2003-2007 period $[7,18,20]$. Despite the improvements in OI incidence and immune recovery, low, stabilized incidences of opportunistic illnesses are still evident in this cohort of patients with AIDS in the 2007-2013 calendar period. The most prevalent OIs in LSOCA were the most common OIs seen in the pre-cART era, and they continue to be the most frequently diagnosed in the modern cART era $[5,6,15,40,41]$.
Because LSOCA enrolled only patients with AIDS, these data uniquely address the effect of cART on late-stage HIV infection. Indeed, the median nadir CD4 T-cell count prior to enrolment of $44 \mathrm{cells} / \mu \mathrm{L}$ indicates that the LSOCA cohort experienced profound levels of immune compromise, and that the benefits of modern CART and the secular trends in the modern cART era are present even among patients with a history of severe immune compromise. Risk factors for OIs and mortality were those expected: lower CD4 T-cell count and higher HIV load.

Patients in the third cohort were more likely to be diagnosed with AIDS based on CD4 T-cell lymphopaenia rather than based on an OI or cancer, which might in part explain the lower mortality incidence in the third cohort. However, AIDS diagnosis category did not have a significant effect 
Table 3 Association of cohort, AIDS diagnosis category and AIDSdefining illnesses at enrolment with mortality

\begin{tabular}{|c|c|c|c|c|}
\hline & Rate $^{*}$ & $\begin{array}{l}\text { No. deaths/ } \\
\text { no. at risk }\end{array}$ & $\mathrm{RR}^{\dagger}$ & $P$ \\
\hline Overall & 37 & $508 / 1889$ & - & - \\
\hline \multicolumn{5}{|l|}{ Enrolment cohort } \\
\hline 1998-2002 & 41 & $409 / 1180$ & 1.00 & - \\
\hline 2003-2005 & 34 & $72 / 329$ & 0.84 & 0.18 \\
\hline 2006-2012 & 18 & $27 / 380$ & 0.46 & 0.0001 \\
\hline \multicolumn{5}{|l|}{ AIDS diagnosis category } \\
\hline $\begin{array}{l}\text { Opportunistic infection } \\
\text { or malignancy }\end{array}$ & 40 & $188 / 654$ & 1.06 & 0.60 \\
\hline CD4 T-cell lymphopaenia & 36 & $320 / 1235$ & 1.00 & - \\
\hline \multicolumn{5}{|l|}{ Opportunistic infections } \\
\hline Any opportunistic infection & 39 & $244 / 862$ & 0.99 & 0.98 \\
\hline No opportunistic infection & 36 & $264 / 1027$ & 1.00 & - \\
\hline Any viral infection & 49 & $2 / 7$ & 2.98 & 0.13 \\
\hline No viral infection & 37 & $506 / 1882$ & 1.00 & - \\
\hline Any parasitic infection & 32 & $19 / 78$ & 1.06 & 0.80 \\
\hline No parasitic infection & 37 & $489 / 1811$ & 1.00 & - \\
\hline Any fungal infection & 39 & $213 / 746$ & 0.99 & 0.96 \\
\hline No fungal infection & 36 & $295 / 1143$ & 1.00 & - \\
\hline Any mycobacterial infection & 44 & $50 / 158$ & 1.02 & 0.92 \\
\hline No mycobacterial infection & 37 & $458 / 1731$ & 1.00 & - \\
\hline Any cancer ${ }^{*}$ & 44 & $43 / 133$ & 1.62 & 0.007 \\
\hline No cancer & 36 & $465 / 1756$ & 1.00 & - \\
\hline
\end{tabular}

$\mathrm{RR}$, relative risk.

*Incidence per 1000 person-years.

${ }^{\dagger}$ Cox models with staggered entries based on time since diagnosis of AIDS. Models were adjusted for age, sex, race, HIV transmissin category, nadir CD4 T-cell count, baseline CD4 T-cell count, baseline and highest recorded HIV loads, and combination antiretroviral therapy.

${ }^{\ddagger}$ AIDS-defining opportunistic infections and cancers.

on mortality, and therefore it is unlikely to have led to a survivor bias in the last cohort. Time since AIDS diagnosis to study enrolment was significantly different among the cohorts. To avoid potential survival bias, we used a staggered entry approach anchoring survival analysis to the AIDS diagnosis date for each patient.

Although the LSOCA cohort enrolled only patients with AIDS, it was not HIV transmission category restricted [35]. Previous analyses suggested that the LSOCA cohort is relatively representative of the AIDS epidemic, with the exception of a slight under-representation of persons whose HIV transmission category is injecting drug use [35]. Therefore, LSOCA is reasonably generalizable to patients with AIDS but not to earlier stages of HIV infection. However, because of late diagnosis of HIV infection and difficulties controlling HIV replication in some patients despite good followup, progression to AIDS does occur [24,32,33], so information on late-stage HIV disease is important, and the LSOCA results uniquely address these patients.

There are limitations to the study. As the outcome of ocular infections (primarily CMV retinitis) was a primary aim of LSOCA, the original cohort oversampled patients with CMV retinitis. However, this analysis focused only on participants without CMV retinitis, minimizing the recruitment bias. As such, the findings should be generalizable to the AIDS epidemic in industrialized countries. The slight under-sampling of injecting drug users does not appear to limit the generalizability of the study, as injecting drug use was not a major risk factor for the outcomes of interest, and there were sufficient numbers of injecting drug users for subgroup analyses. Nevertheless, caution should be exercised in generalizing LSOCA results.

Studies have reported improvements in HIV treatment between 1996 and 2010, during which cART became less toxic, with increased efficacy and higher adherence rates leading to significant decreases in HIV RNA levels $[42,43]$. Our results agree with these reports which focused on the earlier stages of HIV infection and, moreover, show that the efficacy of cART regimens is getting better with time, leading to significant improvements in patient immune health and mortality even among patients with AIDS and a history of severe immune compromise.

In conclusion, this analysis of LSOCA data demonstrates a substantial decline in per-calendar-year rates of OIs among patients with AIDS, with the majority of the decline occurring between 2000 and 2009. All-cause mortality per calendar year showed a steady decline between 2002 and 2013 , corresponding to a $44 \%$ overall reduction in mortality rate and a $64 \%$ reduction in mortality RR by the $2006-$ 2012 enrolment cohort. These results demonstrate ongoing improvements in outcomes among patients with late-stage HIV disease.

\section{Acknowledgements}

We would like to thank Milana R. Isaacson, Kevin P. May and Alka Ahuja for their help in data collection and analysis. The LSOCA participating centres credit roster is presented as Supporting Information Notes S1.

Conflicts of interest: The authors have no conflict of interest to declare.

Financial disclosure: This work was supported by cooperative agreement grants from the National Eye Institute, the National Institutes of Health, Bethesda, MD to the Icahn School of Medicine at Mount Sinai, New York, NY (U10 EY 08052); The Johns Hopkins University Bloomberg School of Public Health, Baltimore, MD (U10 EY 08057); and the University of Wisconsin, Madison School of Medicine, Madison, WI (U10 EY 08067). ES is supported in part by a Johns Hopkins Center for AIDS Research grant (1P30AI094189) from the National Institute of Allergy and Infectious Diseases, the National Institutes of Health, Bethesda, MD, USA; and The Scientific and Technological Research Council of Turkey grant no. 116 C090. 


\section{References}

1 Crum-Cianflone NF, Hullsiek KH, Marconi V et al. Trends in the incidence of cancers among HIV-infected persons and the impact of antiretroviral therapy: authors' reply. AIDS 2009; 23: 1791-1792.

2 Detels R, Tarwater P, Phair JP et al. Effectiveness of potent antiretroviral therapies on the incidence of opportunistic infections before and after AIDS diagnosis. AIDS 2001; 15: 347-355.

3 Gona P, Van Dyke RB, Williams PL et al. Incidence of opportunistic and other infections in HIV-infected children in the HAART era. $J$ Am Med Assoc 2006; 296: 292-300.

4 Hessol NA, Kalinowski A, Benning L et al. Mortality among participants in the Multicenter AIDS Cohort Study and the Women's Interagency HIV Study. Clin Infect Dis 2007; 44: 287-294.

5 Jones JL, Hanson DL, Dworkin MS et al. Surveillance for AIDS-defining opportunistic illnesses, 1992-1997. Morb Mortal Wkly Rep Surveill Summ 1999; 48: 1-22.

6 Jones JL, Hanson DL, Dworkin MS, Ward JW, Jaffe HW. Effect of antiretroviral therapy on recent trends in selected cancers among HIV-infected persons. Adult/Adolescent Spectrum of HIV Disease Project Group. J Acquir Immune Defic Syndr 1999; 21 (Suppl 1): S11-S17.

7 Kaplan JE, Hanson D, Dworkin MS et al. Epidemiology of human immunodeficiency virus-associated opportunistic infections in the United States in the era of highly active antiretroviral therapy. Clin Infect Dis 2000; 30 (Suppl 1): S5-S14.

8 McNaghten AD, Hanson DL, Jones JL, Dworkin MS, Ward JW. Effects of antiretroviral therapy and opportunistic illness primary chemoprophylaxis on survival after AIDS diagnosis. Adult/Adolescent Spectrum of Disease Group. AIDS 1999; 13: 1687-1695.

9 Palella FJ Jr, Baker RK, Moorman AC et al. Mortality in the highly active antiretroviral therapy era: changing causes of death and disease in the HIV outpatient study. $J$ Acquir Immune Defic Syndr 2006; 43: 27-34.

10 Ledergerber B, Egger M, Erard V et al. AIDS-related opportunistic illnesses occurring after initiation of potent antiretroviral therapy: the Swiss HIV Cohort Study. $J$ Am Med Assoc 1999; 282: 2220-2226.

11 Long JL, Engels EA, Moore RD, Gebo KA. Incidence and outcomes of malignancy in the HAART era in an urban cohort of HIV-infected individuals. AIDS 2008; 22: 489-496.

12 Moore RD, Chaisson RE. Natural history of HIV infection in the era of combination antiretroviral therapy. AIDS 1999; 13: 1933-1942.

13 Murphy EL, Collier AC, Kalish LA et al. Highly active antiretroviral therapy decreases mortality and morbidity in patients with advanced HIV disease. Ann Intern Med 2001; 135: 17-26.

14 Nesheim SR, Kapogiannis BG, Soe MM et al. Trends in opportunistic infections in the pre- and post-highly active antiretroviral therapy eras among HIV-infected children in the Perinatal AIDS Collaborative Transmission Study, 19862004. Pediatrics 2007; 120: 100-109.

15 Podlekareva D, Mocroft A, Dragsted UB et al. Factors associated with the development of opportunistic infections in HIV-1-infected adults with high CD4+ cell counts: a EuroSIDA study. J Infect Dis 2006; 194: 633-641.

16 Bonnet F, Chene G, Thiebaut R et al. Trends and determinants of severe morbidity in HIV-infected patients: the ANRS CO3 Aquitaine Cohort, 2000-2004. HIV Med 2007; 8: 547-554.

17 Bonnet F, Lewden C, May T et al. Opportunistic infections as causes of death in HIV-infected patients in the HAART era in France. Scand J Infect Dis 2005; 37: 482-487.

18 Brooks JT, Kaplan JE, Holmes KK, Benson C, Pau A, Masur H. HIV-associated opportunistic infections-going, going, but not gone: the continued need for prevention and treatment guidelines. Clin Infect Dis 2009; 48: 609-611.

19 Buchacz K, Baker RK, Moorman AC et al. Rates of hospitalizations and associated diagnoses in a large multisite cohort of HIV patients in the United States, 1994-2005. AIDS 2008; 22: 1345-1354.

20 Buchacz K, Baker RK, Palella FJ Jr et al. AIDS-defining opportunistic illnesses in US patients, 1994-2007: a cohort study. AIDS 2010; 24: 1549-1559.

21 Gebo KA, Fleishman JA, Moore RD. Hospitalizations for metabolic conditions, opportunistic infections, and injection drug use among HIV patients: trends between 1996 and 2000 in 12 states. J Acquir Immune Defic Syndr 2005; 40: 609-616.

22 Hooshyar D, Hanson DL, Wolfe M, Selik RM, Buskin SE, McNaghten AD. Trends in perimortal conditions and mortality rates among HIV-infected patients. AIDS 2007; 21 : 2093-2100.

23 Lewden C, May T, Rosenthal E et al. Changes in causes of death among adults infected by HIV between 2000 and 2005: the "Mortalite 2000 and 2005" surveys (ANRS EN19 and Mortavic). J Acquir Immune Defic Syndr 2008; 48: 590-598.

24 Mocroft A, Sterne JA, Egger M et al. Variable impact on mortality of AIDS-defining events diagnosed during combination antiretroviral therapy: not all AIDS-defining conditions are created equal. Clin Infect Dis 2009; 48: 1138-1151.

25 Smit C, Geskus R, Walker S et al. Effective therapy has altered the spectrum of cause-specific mortality following HIV seroconversion. AIDS 2006; 20: 741-749.

26 Maurer T, Ponte M, Leslie K. HIV-associated Kaposi’s sarcoma with a high CD4 count and a low viral load. $N$ Engl J Med 2007; 357: 1352-1353. 
27 Mocroft A, Kirk 0, Clumeck N et al. The changing pattern of Kaposi sarcoma in patients with HIV, 1994-2003: the EuroSIDA Study. Cancer 2004; 100: 2644-2654.

28 Palella FJ, Baker RK, Buchacz K et al. Increased mortality among publicly insured participants in the HIV Outpatient Study despite HAART treatment. AIDS 2011; 25: 1865-1876.

29 Puhan MA, Van Natta ML, Palella FJ, Addessi A, Meinert C, Ocular Complications of ARG. Excess mortality in patients with AIDS in the era of highly active antiretroviral therapy: temporal changes and risk factors. Clin Infect Dis 2010; 51: 947-956.

30 Simmons RD, Ciancio BC, Kall MM, Rice BD, Delpech VC. Ten-year mortality trends among persons diagnosed with HIV infection in England and Wales in the era of antiretroviral therapy: AIDS remains a silent killer. HIV Med 2013; 14: 596-604.

31 Jabs DA, Holbrook JT, Van Natta ML et al. Risk factors for mortality in patients with AIDS in the era of highly active antiretroviral therapy. Ophthalmology 2005; 112: 771-779.

32 Finzi D, Blankson J, Siliciano JD et al. Latent infection of $\mathrm{CD} 4+\mathrm{T}$ cells provides a mechanism for lifelong persistence of HIV-1, even in patients on effective combination therapy. Nat Med 1999; 5: 512-517.

33 Grigoryan A, Hall HI, Durant T, Wei X. Late HIV diagnosis and determinants of progression to AIDS or death after HIV diagnosis among injection drug users, 33 US States, 19962004. PLoS ONE 2009; 4: e4445.

34 Schwarcz S, Hsu L, Dilley JW, Loeb L, Nelson K, Boyd S. Late diagnosis of HIV infection: trends, prevalence, and characteristics of persons whose HIV diagnosis occurred within 12 months of developing AIDS. J Acquir Immune Defic Syndr 2006; 43: 491-494.

35 Jabs DA, Van Natta ML, Holbrook JT, Kempen JH, Meinert CL, Davis MD. Longitudinal study of the ocular complications of AIDS - 1. Ocular diagnoses at enrollment. Ophthalmology 2007; 114: 780-786.

36 Jabs DA, van Natta ML, Kempen JH et al. Characteristics of patients with cytomegalovirus retinitis in the era of highly active antiretroviral therapy. Am J Ophthalmol 2002; 133: 48-61.
37 Jabs DA, Van Natta ML, Holbrook JT et al. Longitudinal study of the ocular complications of AIDS: 2. Ocular examination results at enrollment. Ophthalmology 2007; 114: 787-793.

38 Kaplan JE, Benson C, Holmes KK et al. Guidelines for prevention and treatment of opportunistic infections in HIVinfected adults and adolescents: recommendations from CDC, the National Institutes of Health, and the HIV Medicine Association of the Infectious Diseases Society of America. Morb Mortal Wkly Rep 2009; 58: 1-207.

39 Centers for Disease Control and Prevention. 1993 revised classification system for HIV infection and expanded surveillance case definition for AIDS among adolescents and adults. Morb Mortal Wkly Rep 1992; 41: 1-19.

40 Crum-Cianflone N, Hullsiek KH, Marconi V et al. Trends in the incidence of cancers among HIV-infected persons and the impact of antiretroviral therapy: a 20-year cohort study. AIDS 2009; 23: 41-50.

41 Mocroft A, Katlama C, Johnson AM et al. AIDS across Europe, 1994-98: the EuroSIDA study. Lancet 2000; 356: 291-296.

42 Moore RD, Bartlett JG. Dramatic decline in the HIV-1 RNA level over calendar time in a large urban HIV practice. Clin Infect Dis 2011; 53: 600-604.

43 Sax PE. Antiretroviral therapy: now "it just works". Clin Infect Dis 2011; 53: 605-608.

\section{Supporting Information}

Additional Supporting Information may be found in the online version of this article at the publisher's web-site:

Table S1. Three most frequent cART regimens (3+ ARVs) by year of visit (as of 31Dec 2013) in the LSOCA cohort. Table S2. Incidence of AIDS defining illnesses by enrollment cohort.

Notes S1. LS0CA Clinical Centers - Credit Roster Key Personnel (LSOCA certified) 1997 - 2009 